\title{
Comparing the nutrition environment and practices of home- and centre-based child-care facilities
}

\author{
Olivia JM Martyniuk', Leigh M Vanderloo', Jennifer D Irwin ${ }^{2}$, Shauna M Burke ${ }^{2}$ and \\ Patricia Tucker ${ }^{3, *}$ \\ ${ }^{1}$ Health and Rehabilitation Sciences, Faculty of Health Sciences, University of Western Ontario, London, Ontario, \\ Canada: ${ }^{2}$ School of Health Studies, Faculty of Health Sciences, University of Western Ontario, London, Ontario, \\ Canada: ${ }^{3}$ School of Occupational Therapy, Faculty of Health Sciences, University of Western Ontario, 1201 \\ Western Road, Elborn College, Room 2547, London, ON, Canada, N6G 1H1
}

Submitted 27 February 2015: Final revision received 29 September 2015: Accepted 18 November 2015: First published online 6 January 2016

\begin{abstract}
Objective: To assess and compare the nutrition environment and practices (as they relate to pre-schoolers) of centre- and home-based child-care facilities.

Design: Using a cross-sectional study design, nineteen child-care facilities (ten centre-based, nine home-based) were assessed for one full day using the Environment and Policy Assessment and Observation (EPAO) tool (consisting of a day-long observation/review of the nutrition environment, practices and related documents). Specifically, eight nutrition-related subscales were considered.

Setting: Child-care facilities in London, Ontario, Canada.

Subjects: Child-care facilities were recruited through directors at centre-based programmes and the providers of home-based programmes.

Results: The mean total nutrition environment EPAO scores for centre- and homebased facilities were 12.3 (SD 1.94) and 10.8 (SD 0.78) out of 20 (where a higher score indicates a more supportive environment with regard to nutrition), respectively. The difference between the total nutrition environment EPAO score for centre- and home-based facilities was approaching significance $(P=0 \cdot 055)$. For both types of facilities, the highest nutrition subscale score (out of 20) was achieved in the staff behaviours domain (centre mean $=17 \cdot 4$; home mean $=17 \cdot 0$ ) and the lowest was in the nutrition training and education domain (centre mean $=3 \cdot 6$; home mean $=2 \cdot 0$ ).

Conclusions: Additional research is needed to confirm these findings. In order to better support child-care staff and enhance the overall nutrition environment in child care, modifications to food practices could be adopted. Specifically, the nutritional quality of foods/beverages provided to pre-schoolers could be improved, nutrition-related training for child-care staff could be provided, and a nutrition curriculum could be created to educate pre-schoolers about healthy food choices.
\end{abstract}

Nutritious diets are integral to children's healthy growth and development ${ }^{(1,2)}$. Specifically, researchers have demonstrated a clear connection between children's nutrition and both their physical and cognitive health and abilities, inclusive of higher academic performance ${ }^{(3-5)}$. It is important for children to develop healthy eating habits at an early age, as research indicates that food preferences and dietary habits established during childhood can impact their habits in later life ${ }^{(6-8)}$. During the early years, children's eating practices are highly influenced by others, such as family members, caregivers and/or child-care providers $^{(9)}$. Given the increasing prevalence of childhood obesity, healthy nutrition practices are a key element to ensuring appropriate growth and wellness ${ }^{(9-11)}$.

The child-care setting might serve as an ideal venue to initiate the development of pre-schoolers' healthy eating habits and facilitate a positive eating environment. With over half of Canadian pre-schoolers enrolled in child care $^{(12)}$, coupled with the number of meals/snacks prepared and served to pre-schoolers by providers during care hours, the existing gap in Canadian research assessing the nutrition environment in child-care settings (i.e. frequency of food group servings, staff behaviours, nutrition training and policy) is concerning. Investigations 
of the child-care nutrition environment are warranted to ensure that pre-schoolers are being cared for in settings that are conducive to healthy eating ${ }^{(13)}$.

As pre-schoolers tend to consume approximately half to two-thirds of their total daily energy intake while in child care ${ }^{(14,15)}$, this setting is particularly important for influencing the day-to-day nutritional intake of children as well as shaping what they view as normal dietary choices. Researchers who have previously examined the foods and beverages served in the child-care environment ${ }^{(10,16-20)}$ have underscored that the meals and snacks provided to pre-schoolers should be of greater nutritional value. For example, Sisson and colleagues ${ }^{(19)}$ conducted a study of child-care centres in Oklahoma, USA and found that the meat served to young children was frequently high in fat and/or fried, whereas vegetables, high-fibre and whole-grain food options were lacking. Furthermore, work by Erinosho and colleagues ${ }^{(21)}$ indicated that although the staff in many child-care centres in the USA served healthy foods and beverages, increased efforts are necessary for children to meet recommendations in their dietary intake (e.g. increasing the availability of water and vegetables).

With respect to the nutrition environment and feeding practices in child-care settings, researchers in the USA $^{(19,20,22)}$ and the Netherlands ${ }^{(23)}$ have suggested that many of the current nutrition policies (e.g. bringing food from home or holiday/celebration foods), environments (e.g. whether meals are served in prepared portions or 'family style', or the presence of posters about nutrition in the classroom) and feeding practices (e.g. whether staff consume healthy foods in front of children or encourage children to try new foods) could be improved to achieve best practices ${ }^{(24,25)}$. Given that eating habits $^{(26)}$ and food preferences ${ }^{(27,28)}$ can be acquired at a young age, it is essential for child-care providers to act as positive role models and for the child-care environment to be supportive of healthy eating ${ }^{(25)}$.

Currently, there are no national nutrition guidelines for Canadian child-care facilities ${ }^{(28)}$ and consequently, regulations vary across the provinces and territories. This introduces the potential for substantial variation between the nutrition practices in child-care facilities across Canada (and similar differences are apparent in the USA) ${ }^{(29)}$. Also concerning, Romaine et al.'s ${ }^{(30)}$ Canadian study of thirtyfive licensed child-care centres found that less than half of menu planners had undertaken the training recommended by their legislative body (i.e. that menu planning be supervised by a person with child nutrition-related knowledge). Efforts to support healthy nutrition practices in child care are clearly warranted.

Compared with centre-based child-care facilities (which tend to be highly regulated by provincial legislation and share many key features across Canada), less research has focused on nutrition in home-based child-care programmes (which tend to vary substantially as they are privately owned/operated by the child-care providers and run out of their homes) ${ }^{(10)}$. Of the limited studies that concentrate on both settings (i.e. homes and centres), Natale and colleagues ${ }^{(10)}$ found several significant differences in the nutrition and physical activity practices between a large sample of home-based and centre-based facilities in Miami, USA. Consequently, it is important to gather an understanding of the nutrition environment in both types of facilities ${ }^{(10)}$ because $30 \%$ of children under the age of 6 years who receive non-parental care are enrolled in home-based programmes ${ }^{(12)}$. Collecting such information across Canadian provinces is particularly crucial given the lack of comprehensive child-care nutrition regulations and the knowledge that differences, such as resources and regulations, could exist between these two types of child-care settings ${ }^{\text {(31-33) }}$.

In light of the possible variation in food offerings in early learning programmes, the purpose of the present exploratory study was to assess and compare the nutrition environment and practices of home- and centre-based child-care facilities in London, Ontario, Canada as they relate to pre-schoolers.

\section{Methods}

\section{Study design and sample}

Using a cross-sectional study design, and as part of the larger Learning Environments' Activity Potential for Preschoolers (LEAPP) study ${ }^{(34)}$, centre-based and homebased child-care facilities were recruited in London, Ontario, Canada. Full-day kindergarten classrooms were not included in the current analysis as they did not provide food to the children in attendance. Centre-based facilities were randomly selected from a repository which lists child-care centres in London, which listed all centres across the city of London. Various methods were used to recruit home-based facilities (i.e. contacted the London District Home Child Care Network; contacted other child-focused non-profit organizations; placed advertisements in a local magazine and newspaper; posted on social media pages, child-care blogs, etc.) as no central document listing these facilities was available. Additional details regarding recruitment initiatives can be read elsewhere ${ }^{(34)}$.

Data collection was coordinated with child-care directors at centre-based facilities to recruit one classroom within their facility and directly with the child-care providers of the home-based settings. To meet the inclusion criteria for the study, only classrooms within centre-based facilities that provided care to children of pre-school age (i.e. 2.5 to 5 years) were invited to participate. Home-based child-care settings were eligible if the provider cared for at least one child of pre-school age who was not her/his own child. All pre-schoolers in participating facilities received parental/ guardian consent prior to data collection. 
Of the facilities that agreed to participate in the study, one full-day observation of each eligible setting (which contained children of pre-school age) was undertaken between September 2011 and June 2013 by two trained researchers using the Environment and Policy Assessment and Observation (EPAO) tool ${ }^{(35,36)}$. The observation started from the time the first pre-schooler arrived at the setting in the morning and ended when the last child left for the day. Consenting child-care providers were also asked to complete a brief demographic questionnaire to solicit a number of individual- and family-based variables. All study materials and procedures were approved by the University of Western Ontario's Research Ethics Board.

\section{Measures}

Environment and Policy Assessment and Observation (EPAO) tool

The EPAO tool is a reliable and valid measure designed to objectively examine the child-care setting's nutrition and physical activity environment by assessing related policies and practices ${ }^{(36)}$. The tool provides detailed observation procedures (i.e. a protocol) for use in child-care facilities and is used to perform a thorough one-day facility assessment followed by a review of all nutrition and physical activity documents from the facility. However, for the purpose of the present paper, only the nutrition portion of this instrument was of particular focus. Specifically, the following eight nutrition-related subscales were examined by the researchers: (i) fruits and vegetables (e.g. the number of fruit servings provided to pre-schoolers over one day in care); (ii) whole grains and low-fat meats (e.g. the number of lean meat/fish servings); (iii) high-sugar/high-fat foods (e.g. the number of fried/ pre-fried vegetable servings); (iv) beverages (e.g. the number of $100 \%$ fruit juice servings); (v) staff behaviours (e.g. staff pressured children to eat more than they wanted to; staff ate with the children or separately; staff ate the same/different food as children); (vi) nutrition environment (e.g. presence and location of vending machines); (vii) nutrition training and education (e.g. the inclusion of a documented nutrition curriculum); and (viii) nutrition policy (e.g. whether healthier items were encouraged in holiday/celebration food guidelines; see Ward et al ${ }^{\left({ }^{(3)}\right)}$ for a complete description of each subscale).

Two trained researchers spent one full day in each participating facility in order to undertake this assessment. Quietly and unobtrusively, the researchers took a detailed account of each facility's nutrition environment and practices as per the EPAO specifications (e.g. type/ frequency of foods served, staff behaviours/prompts, etc.). If required, the cooks and/or child-care providers were asked to verify uncertainties about food/beverage items (e.g. the percentage of fat in the milk, etc.). Following the observation segment of the EPAO, a review of all nutritionrelated policies and documents (e.g. weekly menus, nutrition policies, nutrition-related training materials for staff and nutrition education opportunities) from the participating facilities was conducted. As the observation procedure consisted of a single day of data collection, weekly menus were examined by the same two researchers to provide a more comprehensive and reliable measure of the frequency and quality of foods/beverages served at the facilities. Menus were also analysed to determine if there was consistency between the number and type of food items served to pre-schoolers and those listed on the written menu for that day of the week. The method by which data were extracted from the facility-provided menus and other nutrition-related documents was dictated by the specifications listed in the document review portion of the EPAO tool ${ }^{(36)}$.

\section{Child-care provider demographic questionnaire}

Participating child-care providers were asked to complete a questionnaire that comprised items such as sex, age, highest level of education completed, type of child-care facility, length of current employment and child-care facility information (e.g. the ratio of children to providers at the facility).

\section{Statistical analysis}

All analyses were carried out using the statistical software package IBM SPSS Statistics version 21. Using the results from the child-care provider demographic questionnaire, frequencies and percentages were calculated for the characteristics of child-care providers.

The EPAO Scoring Guideline developed by Ward et al. $^{(36)}$ was used to derive eight nutrition subscale scores (all out of 20 and based on a combination of items from the observation and document review segments of the tool) for each early learning facility; explicit instructions on how to tally the findings from the EPAO were outlined. For example, to receive a perfect subscale score on the nutrition policy subscale, the centre needed a policy that specifically met the requirements in two out of the nine categories listed in the Nutrition and Physical Activity Self-Assessment for Child Care (NAP SACC) document ${ }^{(24)}$. All item responses from the observation and document review were converted to a three-point scale (ranging from 0 to 2). Individual subscale scores were calculated by averaging the subscale-specific items scores and then multiplied by ten. The eight nutrition-related subscale scores were then averaged to obtain a total nutrition environment EPAO score, out of 20, for each facility. A higher score represents a child-care facility adhering to a greater number of practices supportive of healthy nutrition.

All items within the nutrition portion of the EPAO tool were coded by two reviewers. Intra-class correlation coefficients (ICC) were calculated to examine inter-rater reliability across all eight subscales of the EPAO as well as 
the total nutrition environment EPAO score. All ICC were calculated using an absolute agreement definition. Four subscales had perfect correlation between the two reviewers on the composite scores; as such, ICC values were not calculated for these subscales. ICC were computed for fruits and vegetables (ICC $=0.981$ ), beverages (ICC $=0.988$, whole grains and low-fat meats (ICC $=$ 0.999), high-sugar/high-fat foods (ICC $=0.986$ ), as well as the total nutrition environment EPAO score (ICC = 0.996). Given that all subscale scores represented composite scores, average measures of the ICC were used. Inter-rater reliability analyses were also run on the scores of the subscales that differed between reviewers; the percentage agreement for fruits and vegetables, beverages, whole grains and low-fat meats, high-sugar/high-fat foods and the total nutrition environment EPAO score was $90.6 \%$ ( $\kappa=0.906, P<0.001), 91.1 \%(\kappa=0.911, P<0.001), 95.0 \%$ $(\kappa=0.950, P<0.001), 86.3 \%(\kappa=0.863, P<0.001)$ and $88.1 \%(\kappa=0.881, P<0 \cdot 001)$, respectively; and all suggest near-perfect agreement ${ }^{(37)}$. In light of the high agreement noted between both reviewers' scores, only the scores from Reviewer 1 were used for the purpose of the present paper.

Using the data obtained from the EPAO assessments, overall frequencies and percentages were calculated for the categorical variables for each type of facility (i.e. specific questions from the EPAO observation portion of the tool such as the number and percentage of facilities that served fruit on the day of observation). Means and standard deviations were calculated for each nutrition subscale score (derived from the EPAO Scoring Guideline) according to the type of child-care environment. The means and standard deviations for the total nutrition environment EPAO scores for each type of facility were also calculated. The data's normality was assessed using the Kolmogorov-Smirnov test. The whole grains and low-fat meats, beverages, nutrition environment, nutrition training and education, and nutrition policy subscales were found to be non-normally distributed $(P<0.05)$, and as such, non-parametric Mann-Whitney $U$ tests were used to explore differences in those scores across the centre- and home-based child-care environments. For the remaining subscales that were normally distributed $(P>0.05$; i.e. fruits and vegetables, high-sugar/high-fat foods, staff behaviours and mean total nutrition environment EPAO score), independent-samples $t$ tests were conducted to determine whether subscale scores varied by type of child-care environment.

\section{Results}

\section{Study sample}

A total of nineteen child-care facilities (ten home-based and nine classrooms from centre-based settings) participated in the study. The mean number of children cared for at participating home-based facilities was 4 (range $=3-6$; however, not all children in home-based programmes were of pre-school age) and 11 for pre-school classrooms in centre-based facilities (range $=7-16$ ). During child-care hours, all meals were prepared and provided to the children by the child-care facilities.

Of the participating home-based and centre-based child-care facilities, all providers ( $n$ 36) were female, with the vast majority employed full-time ( $n 34)$. Among centre-based child-care providers ( $n 25$ ), $92 \%$ had completed university or college and $8 \%$ had completed graduate school. Of the home-based child-care providers ( $n$ 11), $72.7 \%$ had completed a university or college degree and none had completed graduate school.

\section{Individual EPAO nutrition subscale scores}

For the eight nutrition subscale scores, the mean for homebased facilities ranged from $2 \cdot 0$ to $17 \cdot 0$ (out of 20) and the mean for centre-based facilities ranged from 3.6 to $17 \cdot 4$ (out of 20; Table 1). While the difference between subscale scores between the two settings neared significance $(P=0.055)$, the whole grains and low-fat meats subscale score was also approaching statistical significance $(P=0 \cdot 059)$. Given the limited sample size and lack of significant variation detected between home- and centre-based child-care settings for both the total nutrition environment EPAO scores and most of the individual nutrition subscale scores, the frequencies and percentages of foods/beverages provided for home- and centre-based facilities were collapsed to represent all participating child-care settings as a whole.

Specific frequencies of food and beverage items served on the day of observation at all facilities, as well as characteristics of the nutrition environment, are discussed below and presented in Tables 2 and 3 .

\section{Fruits and vegetables}

Over half of facilities served fruit twice or more on the day of observation; the majority of facilities met the EPAOrecommended seven or more servings of fruit on their weekly menu, as evidenced by a perfect score on this item. Vegetables were less commonly offered: many facilities did not offer two or more vegetable servings on the observation day and only a third had weekly menus consistent with best practices (i.e. seven or more weekly servings of vegetables, as recommended in the EPAO scoring tool). One dark vegetable serving was provided during the day (see Table 2 for a more detailed description) in over half of the facilities; interestingly, $58.8 \%$ of facilities specified dark vegetables four or more times on their weekly menu and nearly a quarter of the facilities had inconsistencies (i.e. less were served) between their dark vegetable menu listings and actual servings on the day of observation.

\section{Whole grains and low-fat meats}

Fish/lean meats were rare. Beans/lentils were excluded from the weekly menus of over half of the participating 
facilities. Many facilities offered one or more servings of high-fibre grains during the day of observation, but just over a third did not include the EPAO-recommended number of whole grains on their weekly menu (i.e. four servings or greater). In comparison to home-based settings, centrebased facilities adhered to a more favourable practice on two items: the number of times that lean meats/fish was served on the day of observation as well as the number of times that high-fibre grains appeared on the weekly menu.

\section{High-sugar/high-fat foods}

While most facilities did not serve any fried/pre-fried meat items during the observation day, some facilities offered high-fat meats (e.g. ham, pork, pepperoni). Very few facilities refrained from including high-fat meats on their weekly menu. It seemed common practice for facilities to offer high-fat and/or high-sugar foods (e.g. cookies, candies, sweetened cereal; not including condiments) at least once per day, and these food items consistently appeared on all facilities' weekly menus a minimum of four times.

\section{Beverages}

Almost all facilities restricted sugar-based drinks and many appeared to keep $100 \%$ fruit juice servings to a minimum. However, almost a quarter of the facilities' fruit juice menu listings were inconsistent with the items actually served on the observation day (i.e. they served more than what was listed), and just over half of facilities had multiple fruit juice servings listed on their weekly menu. Milk (typically $2 \%$ milk fat) was frequently served to pre-schoolers twice or more per day, and a third of facilities' weekly menus included seven or more servings. While drinking-water was commonly available indoors, it was less available outdoors and staff rarely prompted children to drink water throughout the day whether indoors or outdoors.

\section{Staff behaviours}

Child-care staff sat with children during lunch at most facilities, and the number of facilities where staff did not consume the same food as children was almost as frequent as the number of facilities where they did. Child-care staff were observed consuming less healthy foods in front of the children at only one centre, and staff were not observed eating in three facilities.

\section{Nutrition environment and nutrition policy}

Nutrition-related posters, pictures or books were rarely seen on-site in child-care facilities. A third of facilities either did not have a written policy pertaining to nutrition and food services or they provided no relevant nutritionrelated documentation.

\section{Nutrition training and education}

Staff were observed discussing healthy foods with children in their care at a third of facilities, although few 
Table 2 Frequency of food/beverage items served on the day of observation within the child-care facilities in London, Ontario, Canada, September 2011-June 2013

\begin{tabular}{|c|c|c|c|}
\hline Subscale & Frequency & No. of facilities & Percentage of facilities \\
\hline \multicolumn{4}{|l|}{ Fruits and vegetables } \\
\hline \multirow{3}{*}{ Fruit servings } & 0 & 0 & 0.0 \\
\hline & 1 & 7 & $36 \cdot 8$ \\
\hline & $\geq 2$ & 12 & 63.2 \\
\hline \multirow[t]{3}{*}{ Vegetable servings } & 0 & 1 & $5 \cdot 3$ \\
\hline & 1 & 12 & 63.2 \\
\hline & $\geq 2$ & 6 & 31.6 \\
\hline \multirow[t]{2}{*}{ Dark green, red, orange or yellow vegetable servings } & 0 & 2 & 10.5 \\
\hline & $\geq 1$ & 17 & 89.5 \\
\hline \multicolumn{4}{|l|}{ Grains } \\
\hline \multirow[t]{2}{*}{ Lean meats/fish servings } & 0 & 11 & 57.9 \\
\hline & $\geq 1$ & 8 & $42 \cdot 1$ \\
\hline \multirow[t]{2}{*}{ High-fibre grain servings } & 0 & 6 & 31.6 \\
\hline & $\geq 1$ & 13 & $68 \cdot 4$ \\
\hline \multirow[t]{2}{*}{ Beans/lentil servings } & 0 & 14 & 73.7 \\
\hline & $\geq 1$ & 5 & $26 \cdot 3$ \\
\hline \multicolumn{4}{|l|}{ High-fat/high-sugar foods } \\
\hline \multirow[t]{2}{*}{ Fried/pre-fried meat servings } & 0 & 18 & 94.7 \\
\hline & 1 & 1 & $5 \cdot 3$ \\
\hline \multirow[t]{2}{*}{ High-fat meat servings } & 0 & 13 & $68 \cdot 4$ \\
\hline & $\geq 1$ & 6 & 31.6 \\
\hline \multirow[t]{3}{*}{ High-fat and/or high-sugar food servings (not including condiments) } & 0 & 3 & $15 \cdot 8$ \\
\hline & 1 & 11 & 57.9 \\
\hline & $\geq 2$ & 5 & $26 \cdot 3$ \\
\hline \multirow[t]{3}{*}{ High-fat and/or high-sugar condiment servings } & $0-1$ & 12 & 63.2 \\
\hline & 2 & 5 & $26 \cdot 3$ \\
\hline & $\geq 3$ & 2 & $10 \cdot 6$ \\
\hline \multicolumn{4}{|l|}{ Beverages } \\
\hline \multirow[t]{3}{*}{$100 \%$ fruit juice servings } & 0 & 11 & 57.9 \\
\hline & 1 & 6 & 31.6 \\
\hline & $\geq 2$ & 2 & $10 \cdot 6$ \\
\hline \multirow[t]{2}{*}{ Sugar drink servings } & 0 & 18 & 94.7 \\
\hline & $\geq 1$ & 1 & $5 \cdot 3$ \\
\hline \multirow[t]{3}{*}{ Milk servings } & 0 & 1 & $5 \cdot 3$ \\
\hline & 1 & 7 & $36 \cdot 8$ \\
\hline & $\geq 2$ & 11 & 57.9 \\
\hline \multirow[t]{4}{*}{ Type of milk served on day of observation } & Whole & 1 & $5 \cdot 3$ \\
\hline & $2 \%$ & 14 & 73.7 \\
\hline & $1 \%$ & 3 & $15 \cdot 8$ \\
\hline & Skimmed & 1 & $5 \cdot 3$ \\
\hline \multirow[t]{2}{*}{ Was drinking water available indoors? } & Yes & 15 & 78.9 \\
\hline & No & 4 & $21 \cdot 1$ \\
\hline \multirow[t]{2}{*}{ Was drinking water available outdoors? } & Yes & 5 & $26 \cdot 3$ \\
\hline & No & 12 & 63.2 \\
\hline \multirow[t]{2}{*}{ Did staff prompt children to drink water throughout the day? } & Yes & 1 & $5 \cdot 3$ \\
\hline & No & 18 & 94.7 \\
\hline \multirow{2}{*}{ While outdoors, did staff prompt children to drink water? } & Yes & 0 & 0.0 \\
\hline & No & 15 & 78.9 \\
\hline
\end{tabular}

Column totals may not add up to the total number of facilities observed (i.e. $n$ 19) as outdoor playtime did not always occur, staff were not observed eating at every facility, or if the facility did not provide a weekly menu. All items presented in this table were measured via the observation portion of the EPAO (Environment and Policy Assessment and Observation) tool.

facilities provided any formal nutrition education to the pre-schoolers in care. Most facilities had neither a nutrition curriculum nor nutrition training for staff.

\section{Total nutrition environment EPAO score for all child-care settings}

While the difference between the two types of child-care arrangements for the mean total nutrition environment EPAO scores was approaching significance (Table 1; $P=0.055)$, the centre-based facilities (12.12 out of 20$) \mathrm{did}$ score slightly higher in comparison to the home-based ones (9.81 out of 20).

\section{Discussion}

The present study was the first Canadian exploratory study to objectively assess and compare the environmental factors related to 2.5- to 5-year-old pre-schoolers' nutritional intake (e.g. types/frequency of foods served, training and education, policies, staff behaviours, etc.) across a sample of home- and centre-based child-care programmes in London, Ontario, Canada. While studies have explored the nutrition environment of child-care facilities internationally ${ }^{(10,16,19,20,22)}$, this environment is not well understood in Canada and research comparing the nutrition-related policies and practices in 
Table 3 Nutrition practices among child-care facilities in London, Ontario, Canada, September 2011-June 2013

\begin{tabular}{|c|c|c|c|c|}
\hline Subscale & $\begin{array}{l}\text { Method of } \\
\text { assessment }\end{array}$ & Frequency & $\begin{array}{l}\text { No. of } \\
\text { facilities }\end{array}$ & $\begin{array}{l}\text { Percentage o } \\
\text { facilities }\end{array}$ \\
\hline \multicolumn{5}{|l|}{ Staff behaviours } \\
\hline \multirow{2}{*}{$\begin{array}{l}\text { Did staff push children to eat more than they } \\
\text { wanted to? }\end{array}$} & \multirow[t]{2}{*}{ Observation } & Yes & 3 & $15 \cdot 8$ \\
\hline & & No & 16 & $84 \cdot 2$ \\
\hline \multirow{3}{*}{$\begin{array}{l}\text { Did staff positively/gently encourage children to } \\
\text { eat new or less familiar foods? }\end{array}$} & \multirow{3}{*}{ Observation } & Yes & 8 & $42 \cdot 1$ \\
\hline & & No & 1 & $5 \cdot 3$ \\
\hline & & No resisting observed & 10 & 52.6 \\
\hline \multirow{2}{*}{$\begin{array}{l}\text { Did staff sit with children during lunch on day } \\
\text { of observation? }\end{array}$} & \multirow[t]{2}{*}{ Observation } & Yes & 14 & 73.7 \\
\hline & & No & 5 & $26 \cdot 3$ \\
\hline \multirow{2}{*}{ Did staff consume the same food as children? } & \multirow[t]{2}{*}{ Observation } & Yes & 7 & $36 \cdot 8$ \\
\hline & & No & 6 & 31.6 \\
\hline \multirow{3}{*}{$\begin{array}{l}\text { Did staff eat or drink less healthy foods in front } \\
\text { of children on day of observation? }\end{array}$} & \multirow[t]{3}{*}{ Observation } & Yes & 1 & $5 \cdot 3$ \\
\hline & & No & 15 & 78.9 \\
\hline & & Staff not observed eating & 3 & $15 \cdot 8$ \\
\hline \multicolumn{5}{|l|}{ Nutrition environment } \\
\hline \multirow{3}{*}{ How was lunch served (on day of observation)? } & \multirow[t]{3}{*}{ Observation } & Family style & 5 & $26 \cdot 3$ \\
\hline & & Delivered in prepared portions & 9 & $47 \cdot 4$ \\
\hline & & Portioned by staff & 5 & $26 \cdot 3$ \\
\hline \multirow{2}{*}{$\begin{array}{l}\text { Were there any posters, pictures or books about } \\
\text { nutrition displayed in the classroom? }\end{array}$} & \multirow[t]{2}{*}{ Observation } & Yes & 1 & $5 \cdot 3$ \\
\hline & & No & 18 & 94.7 \\
\hline \multicolumn{5}{|l|}{ Nutrition training \& education } \\
\hline \multirow{2}{*}{$\begin{array}{l}\text { Did staff talk with children about healthy foods } \\
\text { (on day of observation)? }\end{array}$} & \multirow[t]{2}{*}{ Observation } & Yes & 7 & $36 \cdot 8$ \\
\hline & & No & 12 & 63.2 \\
\hline \multirow{2}{*}{$\begin{array}{l}\text { Was any formal nutrition education for kids } \\
\text { observed (on day of observation)? }\end{array}$} & \multirow[t]{2}{*}{ Observation } & Yes & 1 & $5 \cdot 3$ \\
\hline & & No & 18 & 94.7 \\
\hline \multirow{2}{*}{$\begin{array}{l}\text { Does centre have documentation for nutrition } \\
\text { curriculum (on day of observation)? }\end{array}$} & \multirow[t]{2}{*}{ Observation } & Yes & 2 & 10.5 \\
\hline & & No & $1 \overline{7}$ & 89.5 \\
\hline \multirow{3}{*}{$\begin{array}{l}\text { Does centre provide nutrition training for staff } \\
\text { (on day of observation)? }\end{array}$} & \multirow[t]{3}{*}{ Observation } & Yes & 1 & $5 \cdot 3$ \\
\hline & & No & 15 & $78 \cdot 9$ \\
\hline & & No documents received & 3 & $15 \cdot 8$ \\
\hline \multicolumn{5}{|l|}{ Nutrition policy } \\
\hline \multirow{3}{*}{$\begin{array}{l}\text { Does the centre have a written policy on } \\
\text { nutrition and food service? }\end{array}$} & \multirow{3}{*}{$\begin{array}{l}\text { Document } \\
\text { review }\end{array}$} & Yes & 12 & 63.2 \\
\hline & & No & 3 & $15 \cdot 8$ \\
\hline & & No documents received & 4 & $21 \cdot 1$ \\
\hline
\end{tabular}

Column totals may not add up to the total number of facilities observed (i.e. $n$ 19) as outdoor playtime did not always occur, staff were not observed eating at every facility, or if the facility did not provide a weekly menu.

home- $v$. centre-based child-care facilities is limited. When comparing the overall nutrition environment of centre- and home-based facilities, results from the study indicate that a possible trend exists in favour of centre-based facilities. Future explorations that include a larger sample size could help to confirm if these differences exist and the specific aspects of the nutrition environment which account for these differences. Overall, findings from our initial study suggest that the nutrition environment within both types of child-care programme may require improvement. Specific environmental factors that influence the nutrition-related choices and practices of children during their time in these programmes are discussed below. Child-care professionals, researchers, policy makers and public health professionals could collaborate to develop provincial guidelines (and subsequent training) that support child-care facilities to create a healthier nutrition environment by making improvements in the following areas: food and beverage servings; staff behaviours; nutrition training and education; and nutrition policy.

\section{Food and beverage servings}

Of the domains measuring foods and beverages served to pre-schoolers, the fruits and vegetables domain showed the most encouraging results. On the day of observation, child-care facilities also achieved particularly positive scores pertaining to: (i) fruit servings provided to children and appearing on the weekly menu; (ii) dark vegetable servings; (iii) high-fibre grain servings; and (iv) a limited number of high-fat or fried/pre-fried meat items served. Our observation that most facilities met best practices for the number of fruit servings is consistent with other studies $^{(16,19,20)}$. As discussed by Nicklas et al. ${ }^{(27)}$, childcare meals are opportune times for pre-schoolers to continually be exposed to healthy items, as researchers have demonstrated that repeated exposure to food items might influence development of food preferences ${ }^{(38,39)}$.

Based on the findings from the present study, designing child-care menus to ensure pre-schoolers receive adequate servings of vegetables in general and dark vegetables in particular should be a priority. Additionally, we found that high-fibre products such as whole grains and beans/lentils are not consistently included in childcare menus for pre-schoolers. In Nova Scotia, Canada, Romaine and colleagues ${ }^{(30)}$ found that child-care centre menus did not consistently include beans, peas, lentils and other legumes; all items recognized as important sources of Fe, fibre, folate and protein. Given the number of meals 
and snacks served in care, child-care facilities have the opportunity to help shape children's standard mealtime routine by providing vegetables as well as whole grains and legumes as a part of each meal; modifications to menu planning within the child-care environment are needed.

\section{Staff behaviours}

Of the eight subscales, staff behaviour received the highest score. Of the staff behaviours observed, the staff at the majority of child-care programmes $(73.7 \%)$ sat with the pre-schoolers during meals and rarely consumed unhealthy foods in front of the children. Maalouf et $a l^{(20)}$ and Erinosho et al $^{(22)}$ also reported that the staff in their studies rarely ate unhealthy foods in front of pre-schoolers in care; however, in Maalouf et al.'s study ${ }^{(20)}$, staff rarely sat with children during mealtimes. The work by Gubbels et al. ${ }^{(23)}$ found that providers' eating practices within the centre-based child-care environment were highly associated with children's dietary intake. Interestingly, all staff in our study did not tend to consume the same food as the children in their care. Given that children of pre-school age are more likely than older children to be influenced by adult figures at mealtimes ${ }^{(40)}$, emphasizing the importance of child-care providers modelling healthy eating and nutrition behaviours is key. The child-care venue presents a unique opportunity for providers to use enthusiastic modelling to encourage pre-schoolers' healthy eating, especially because such demonstration has been recognized as an effective way to influence children's eating practices ${ }^{(14,23,25,41,42)}$. Future research could build on the present study to see if nutrition policies around staff's food consumption (whether their food choices are consistent with what is served at the child-care facilities or whether they choose to bring their own food from home) influence their modelling of healthy eating and nutrition behaviours to the children in their care.

\section{Nutrition training and education}

The present study revealed that nutrition training and education at participating child-care facilities warrants the most attention. In fact, Benjamin Neelon et al. ${ }^{(16)}$ recognized that 'although childcare providers have a responsibility to serve nutritious meals and snacks, they often receive limited training and little guidance in creating environments that support healthy eating' (p. 216). Data from the present study showed that it was rare for childcare facilities to have a documented nutrition curriculum for pre-schoolers in care or to offer nutrition training for staff. The significance of nutrition education for children as well as nutrition training for staff is well documented ${ }^{(16,25,43)}$. Evidently, nutrition-related training and education for staff, and the development of a nutrition curriculum for pre-schoolers, should be viewed as a priority moving forward to support healthy eating among pre-schoolers. Additionally, education/training for menu planners and cooks may also help ensure foods prepared are nutritionally adequate as well as appealing to young children $^{(21)}$. In light of the lack of training provided to child-care staff and cooks, combined with the variation in regulations regarding menu review by dietitians, ample room exists to improve the menu planning process in London child-care facilities.

\section{Nutrition policy}

The findings from the current preliminary work indicate that nutrition policies within child-care facilities in London, Ontario are lacking. In comparison to Ontario, the Manual for Food and Nutrition in Regulated Child Care Settings in Nova Scotia provides a more stringent and comprehensive set of recommendations including extra sections on healthy modelling of food ${ }^{(44)}$, family involvement and foods not to serve. As per the recommendations from the Ontario Society of Nutrition Professionals in Public Health $^{(15)}$, the Day Nurseries Act should be updated to a version similar to Nova Scotia's and appropriately reflect changes in Canada's Food Guide. Since the publications of these recommendations, the Ontario Government has recognized that the nutrition requirements in Regulation 262 are 'significantly outdated' and has recently proposed amendments to the nutrition requirements (e.g. 'follow the latest version of Canada's Food Guide, have menus reviewed by a registered dietician, and establish policies/ procedures describing their approach to providing high-quality meals/snacks and positive meal time experiences' $)^{(45)}$. Based on the research from the NAP SACC self-assessment tool $^{(24,36)}$, the policies created should promote positive nutrition through topics such as menus and variety, foods offered outside regular mealtimes, nutrition education, etc.

Implementing policies at child care could be one effective avenue to improve the overall nutrition environment. Previous research by Erinosho's team ${ }^{(22)}$ found that while some policies around healthy modelling were associated with healthier staff nutrition behaviours, the mere presence of such policies did not always result in healthier staff behaviours; however, these researchers questioned if the policies were fully enforced. Ward et al.'s ${ }^{(46)}$ recent work with experts and stakeholders also echoed the concern that many nutrition and physical activity-related child-care policies with positive intentions have been implemented, yet achieve limited results. It might be the case that policies, combined with effective staff training and education, might be a more effective and realistic solution.

\section{Strengths and limitations}

The present study contributes to the scarce body of research that compares the nutrition environment across child-care settings in Canada and a strength of the work was the use of direct-observation methods to collect data 
via a valid and reliable tool. While the current paper highlights important preliminary findings regarding the nutrition environment in home- and centre-based childcare facilities, it is not without its limitations. First, the EPAO tool has been validated to use within centre-based child-care facilities ${ }^{(36)}$, but not within home-based programmes. Consequently, the appropriateness and validity of the findings solicited from this single-day observation, albeit direct, may have been compromised for the home-based sample. Second, the EPAO failed to capture information on all types of food served within the child-care environment including cheese, yoghurt and eggs, all of which appeared to be popular food choices among the participating facilities in the study. Collecting such data would undoubtedly provide a more accurate picture of the nutrition environment and menus developed within this unique setting. Third, it is also important to note that food actually consumed by the pre-schoolers was not measured; only the availability and number of servings were observed. Therefore, there may be some discrepancy between what was available and what was actually consumed; having this information would provide a more accurate picture of the nutritional intake of children in care. Fourth, as only nineteen child-care facilities were included in the study, caution should be taken when interpreting the results. Lastly, while every effort was made to ensure a representative sample (i.e. geographic areas, socio-economic status, etc.), this was not always possible as there was no single repository listing all home-based child-care facilities across the city (which therefore may have resulted in some selection bias). While it is likely that the centre-based facilities in the present study may share a number of similarities with other cross-country facilities based on comparable legislation, variation is expected to exist between home-based facilities as they are individually operated and managed out of their child-care provider's home. As such, the generalizability of our findings may have been impacted.

\section{Conclusions}

This is the first Canadian study tasked with exploring and comparing the nutrition environment of pre-schoolers attending home- and centre-based child-care facilities. The findings of this work highlighted some strengths and weaknesses with regard to the nutrition environment across both types of child-care settings, including the lack of significant differences between these two settings. Additional research is needed to further explore and confirm these findings. Future work is recommended to develop policies pertaining to the nutrition environment in child-care settings and the impact of these policies on nutritional practices. The present findings suggest that support for child-care staff (e.g. through guidelines and training) may be needed, and that such changes may also help guide the ratification of current legislation to provide more specific direction around nutrition in child-care facilities. Child-care directors could collaborate with nutrition professionals to increase the nutritionrelated training for child-care menu planners and early childhood educators, to help improve the nutritional quality of foods and beverages served to pre-schoolers. These groups could also work together to create a nutrition curriculum in order to provide nutrition education to pre-schoolers.

\section{Acknowledgements}

Acknowledgements: The authors wish to thank the home- and centre-based child-care facilities that agreed to participate in this study. The authors are also grateful to the pre-schoolers and their families for their involvement. Thanks are extended to Dr Courtney Newnham-Kanas for her assistance with data collection and reviewing sections of the manuscript, and to Emie Angeles for helping with data entry. Financial support: This project was funded by the Canadian Institutes of Health Research, the Heart and Stroke Foundation of Canada and the Public Health Agency of Canada (P.T., CIHR Award \# GIR 112690). The Canadian Institutes of Health Research, the Heart and Stroke Foundation of Canada and the Public Health Agency of Canada had no role in the design, analysis or writing of this article. Conflict of interest: None. Authorship: P.T., J.D.I. and S.M.B. were all involved with the conception, design and implementation of the study. O.J.M.M. and L.M.V. carried out data collection/analyses and drafted the manuscript; P.T., J.D.I. and S.M.B. provided their expertise, revisions and comments on the manuscript. Ethics of human subject participation: This study was conducted according to the guidelines laid down in the Declaration of Helsinki and all procedures involving human subjects were approved by the University of Western Ontario's Research Ethics Board. Written informed consent was obtained from all child-care centre directors and child-care providers of home-based programmes, and all pre-schoolers received written parental/guardian consent.

\section{References}

1. Engle P \& Huffman SL (2010) Growing children's bodies and minds: maximizing child nutrition and development. Food Nutr Bull 31, 2 Suppl., S186-S197.

2. Feinstein L, Sabates R, Sorhaindo A et al. (2008) Dietary patterns related to attainment in school: the importance of early eating patterns. J Epidemiol Community Health 62, 734-739.

3. National Association of State Boards of Education (2002) Fit, Healthy, Ready to Learn: A School Health Policy Guide. Alexandria, VA: National Association of State Boards of Education. 
4. Penney TL \& McIssac JL (2012) Describing the Link Between School Performance, Healthy Eating and Physical Activity in Children and Youth: A Research Synthesis. Ottawa, ON: Heart and Stroke Foundation of Canada.

5. Papamandjaris A (2002) Breakfast and Learning in Children: A Review of the Effects of Breakfast on Scholastic Performance. North York, ON: Breakfast for Learning, Canadian Living Foundation.

6. Birch L (1999) Development of food preferences. Annu Rev Nutr 19, 41-62.

7. Parcel GS, Perry CL, Kelder SH et al. (2003) School climate and the institutionalization of the $\mathrm{CATCH}$ program. Health Educ Behav 30, 489-502.

8. Mikkila V, Rasanen L, Raitakari OT et al. (2005) Consistent dietary patterns identified from childhood to adulthood: the Cardiovascular Risk in Young Finns Study. BrJ Nutr 93 , 923-931.

9. Birch LL \& Ventura AK (2009) Preventing childhood obesity: what works? Int J Obes (Lond) 33, Suppl. 1, S74-S81.

10. Natale R, Page M \& Sanders L (2014) Nutrition and physical activity practices in childcare centers versus family childcare homes. Early Child Educ J 42, 327-334.

11. Berg F, Buechner J \& Parham E (2003) Guidelines for childhood obesity prevention programs: promoting healthy weight in children. J Nutr Educ Behav 35, 1-4.

12. Bushnik T (2006) Child Care in Canada. Children and Youth Research Paper Series. Ottawa, ON: Statistics Canada.

13. Geoffroy MC, Power C, Touchette E et al. (2012) Childcare and overweight or obesity over 10 years of follow-up. J Pediatr 162, 753-758.

14. Gidding SS, Dennison BA, Birch LL et al. (2005) Dietary recommendations for children and adolescents. Circulation 112, 2061-2075.

15. Ontario Society of Nutrition Professionals in Public Health (2010) Recommendations on Modernizing Child Care in Ontario. Toronto, ON: Ontario Society of Nutrition Professionals in Public Health.

16. Benjamin Neelon SE, Vaughn A, Ball SC et al. (2012) Nutrition practices and mealtime environments of North Carolina child-care centers. Child Obes 8, 216-223.

17. Briley ME, Jastrow S, Vickers J et al. (1999) Dietary intake at child-care centers and away: are parents and care providers working as partners or at cross-purposes? J Am Diet Assoc 99, 950-954.

18. Erinosho TO, Ball SC, Hanson PP et al. (2013) Assessing foods offered to children at child-care centers using the Healthy Eating Index. J Acad Nutr Diet 113, 1084-1089.

19. Sissons SB, Campbell JE, May KB et al. (2012) Assessment of food nutrition, and physical activity practice in Oklahoma child-care centers. J Acad Nutr Diet 112, 1230-1240.

20. Maalouf J, Evers S, Griffin M et al. (2013) Assessment of mealtime environments and nutrition practices in child care centers in Georgia. Child Obes 9, 437-445.

21. Erinosho T, Dixon LB, Young C et al. (2011) Nutrition practices and children's dietary intakes at 40 child-care centers in New York City. J Am Diet Assoc 111, 1391-1397.

22. Erinosho TO, Hales DP, McWilliams CP et al. (2012) Nutrition policies at child-care centers and impact on role modeling of healthy eating behaviors of caregivers. J Acad Nutr Diet 112, 119-124.

23. Gubbels JS, Kremers SPJ, Stafleu A et al. (2010) Child care environment and dietary intake of 2-3 year old children. J Hum Nutr Diet 23, 97-101.

24. Ammerman ASWD, Benjamin SE, Ball SC et al. (2007) An intervention to promote healthy weight: nutrition and physical activity self-assessment for child care (NAP SACC) theory and design. Prev Chronic Dis 4, A67.

25. Benjamin Neelon SE \& Briley ME (2011) Position of the American Dietetic Association: benchmarks for nutrition in child care. J Am Diet Assoc 111, 607-615.
26. Larson N, Story M, Wall M et al. (2006) Calcium and diary intakes of adolescents are associated with their home environment, taste preferences, personal health beliefs, and meal patterns. J Am Diet Assoc 106, 1816-1824.

27. Nicklas TA, Baranowski JC, Baranoski T et al. (2014) Family and child-care provider influences on preschool children's fruit, juice, and vegetable consumption. Nutr Rev 59, 224-235.

28. Skinner JD, Carruth BR, Wendy B et al. (2002) Children's food preferences: a longitudinal analysis. J Am Diet Assoc 102, 1638-1647.

29. Benjamin SE, Cradock A, Walker EM et al. (2008) Obesity prevention in child care: a review of US state regulations. BMC Public Health 8, 188.

30. Romaine N, Mann L, Kienapple K et al. (2007) Menu planning for childcare centres: practices and needs. Can J Diet Pract Res 68, 7-13.

31. Natale R, Scott SH, Messiah SE et al. (2013) Design and methods for evaluating an early childhood obesity prevention program in the childcare center setting. BMC Public Health 13, 78.

32. Kaphingst KM \& Story M (2009) Child care as an untapped setting for obesity prevention: state child care licensing regulations related to nutrition, physical activity, and media use for preschool-age children in the US. Prev Chronic Dis 6, A11.

33. Tandon PS, Garrison MM \& Christakis DA (2012) Physical activity and beverages in home- and center-based child care program. J Nutr Educ Behav 44, 355-358.

34. Tucker P, Vanderloo L, Newnham-Kanas C et al. (2013) Learning environments' activity potential for preschoolers (LEAPP): study rationale and design. J Public Health Res 2, 113-117.

35. Ball SC, Benjamin SE, Hales DP et al. (2005) The Environment and Policy Assessment and Observation (EPAO) Child Care Nutrition and Physical Activity Instrument. Chapel Hill, NC: University of North Carolina, Center for Health Promotion and Disease Prevention.

36. Ward D, Hales D, Haverly K et al. (2008) An instrument to assess the obsogenic environment of child care centers. Am J Health Behav 32, 380-386.

37. Landis JR \& Koch GG (1977) The measurement of observer agreement for categorical data. Biometrics 33, 159-174.

38. Pliner $\mathrm{P}$ (1982) The effects of mere exposure on liking for edible substances. Appetite 3, 283-290.

39. Stark LJ, Collins FL, Osnes PG et al. (1986) Using reinforcement and cueing to increase healthy snack food choices in preschoolers. J Appl Behav Anal 19, $367-379$

40. Addessi E, Galloway AT, Visalberghi E et al. (2005) Specific social influences on the acceptance of novel foods in 2-5 year old children. Appetite 45, 264-271.

41. Wilkinson D \& McCargar L (2008) Prevention of Overweight and Obesity in Young Canadian Children. Toronto, ON: Canadian Council of Food and Nutrition.

42. Hendy HM \& Raudenbush B (2000) Effectiveness of teacher modeling to encourage food acceptance in preschool children. Appetite 34, 61-76.

43. Fuller C, Keller L, Olson J et al. (2005) Helping preschoolers become healthy eaters. J Pediatr Health Care 19, 178-182.

44. Government of Nova Scotia (2011) Manual for Food and Nutrition in Regulated Child Care Settings. Halifax, NS: Government of Nova Scotia.

45. Ministry of Education (2013) Proposal to Amend Regulation 262 under the Day Nurseries Act - Child Care Modernization Document. http://www.ontariocanada.com/registry/view. do?postingId=14762 (accessed September 2014).

46. Ward DS, Vaughn A \& Story M (2013) Expert and stakeholder consensus on priorites for obesity prevention research in early care and education settings. Child Obes 9, 116-124. 